\title{
Does an educational workshop have an impact on caregivers' levels of knowledge about cerebral palsy? A comparative, descriptive cross-sectional survey of Zimbabwean caregivers
}

\author{
Jermaine M. Dambi, Celia Mandizvidza, Matthew Chiwaridzo, Clement Nhunzvi, \\ Cathrine Tadyanemhandu
}

Department of Rehabilitation, College of Health Sciences, University of Zimbabwe, Harare, Zimbabwe

Correspondence: Mr Jermaine M. Dambi (jermainedambi@gmail.com)

\begin{abstract}
Background
Methods

Results $77.0, Z=-4.45$, and $\mathrm{P}<0.001)$.

Conclusions

\section{Introduction}

Diagnosis of a child with a lifelong disability, such as cerebral palsy (CP), can be catastrophic to parents or caregivers. ${ }^{1}$ It is often accompanied by feelings of despair, anxiety, hopelessness, and the fear of the unknown. ${ }^{1-5}$ Predominantly, $\mathrm{CP}$ is known for causing disturbances in movement and posture, often accompanied by disturbances in cognition and perception, and resulting in profound activity limitations for affected children, with delayed attainment of developmental milestones. ${ }^{6}$ Further, CP is a lifelong condition with a complex and variable presentation and is the most common childhood disability worldwide..$^{6-10}$
\end{abstract}

The diagnosis of a child with a life-long disability, such as cerebral palsy (CP), can be catastrophic to parents. It is often accompanied by feelings of despair, anxiety, hopelessness, and the fear of the unknown. Knowledge about CP is thus essential for caregiver adjustment and preparation for the caregiving role. However, there is a paucity of empirical evidence regarding the best method for educating caregivers. The aim of this study was therefore to evaluate the impact of an educational intervention on caregivers' knowledge about cerebral palsy.

This cross-sectional survey included 49 caregivers of children with cerebral palsy. Convenience sampling was used to select participants from two central hospitals in Harare, Zimbabwe. The caregivers were divided into two groups based on whether or not they had attended an educational workshop. The knowledge of cerebral palsy questionnaire (KCPQ) was administered once to assess the caregivers' CP knowledge.

The caregivers were comparable in terms of sociodemographic characteristics. The mean KCPQ scores for caregivers who attended workshops was 17.4 (SD 1.5), versus 13.8 (SD 2.5) for those without exposure to workshops. The differences between the two groups was statistically significant $(\mathrm{U}=$

Our findings suggest that educational workshops may lead to improved CP knowledge among caregivers. This may better equip parents and guardians to meet the extra caregiving demands associated with CP, leading to improved health outcomes for children with CP and their caregivers.

Invariably, most children with $\mathrm{CP}$ require assistance with the performance of day-to-day activities, such as feeding, bathing, and dressing, among others. ${ }^{11,12}$ In low-resource settings, parents and the immediate family are usually the primary caregivers. ${ }^{11,13}$ Unfortunately, these caregivers are not always well-equipped or formally trained to assume the caregiving role, as opposed to formal caregivers, such as nurse aides. ${ }^{14,15}$ In contrast, a formal caregiver, by definition, is someone who is formally trained and remunerated for provision of care to someone with special healthcare needs. ${ }^{14}$ Unfortunately, provision of care for a child with a lifelong disability has been shown to lead to poor health outcomes among informal caregivers. ${ }^{16}$ Empirical evidence from a systematic review suggests that provision of care for a child with CP is often associated with anxiety, pain, depression, financial strain, and poor health outcomes among informal caregivers. ${ }^{12}$ Overall, caring for a child with a disability can have a negative impact on the life of a caregiver, especially if the caregive feels inadequate, or if the caregiver fails to meet the child's needs. ${ }^{17}$ To this end, it is hypothesised that caregivers who are more knowledgeable about $\mathrm{CP}$ are more likely to adjust and cope with the demands of caregiving. ${ }^{18}$ Studies have shown that knowledgeable caregivers are likely to exhibit high self-efficacy and report positive psychosocial indices and better health-related quality of life (HRQoL). ${ }^{19}$ Furthermore, appropriate care can only be given if caregivers have pertinent information and skills to meet a child's needs. ${ }^{20}$ Therefore, healthcare professionals play an essential role in diagnosis, treatment, advocacy, and health education. ${ }^{5,21}$ To this end, various methods of information provision have been one session with a healthcare practitioner. In essence, most parents and caregivers learn about CP upon diagnosis of the condition. ${ }^{10}$ It is the obligation of the healthcare practitioner to provide information on the condition, as diagnosis of $\mathrm{CP}$ is often a mystery to caregivers. ${ }^{24}$ The inherent weakness of this method is that there may be minimal time to fully explain the complexity of $\mathrm{CP}$ in a single session. This is even more true in low-resource settings, where there is a high patient-toprovider ratio. Consequently, caregivers may not be afforded the opportunity to comprehensively learn about their child's diagnosis. Alternative educational methods, such as the use of multimedia (including videos and the Internet) ${ }^{18}$ may also have minimal efficacy as caregiver educational strategies in low-resource settings.

To this end, in Zimbabwe, the Children's Rehabilitation Unit (CRU), which is based at Harare Central Hospital, conducts caregivers' training workshops for educating caregivers on various neurodevelopmental disorders. By definition, workshops are educational interventions aimed at giving groups of caregivers the necessary knowledge and skillsoutlined in the literature. The most basic method is a one-on- 
through lectures, role playing, and other demonstrationsabout a certain health condition. ${ }^{22,23}$ As for the CP workshops, caregivers are taught about the presentation, aetiology, and management aspects of CP. Various healthcare personnel, such as physiotherapists, occupational therapists, rehabilitation technicians, speech therapists, nurses, social workers, and counsellors, facilitate the workshops. There is evidence that educational interventions may increase caregiver knowledge and skill in providing care and subsequently increase parenting self-efficacy and decrease in stress levels. ${ }^{2,24}$ However, there is a dearth of empirical evidence of the impact of various educational strategies used to impact knowledge of CP among caregivers in Zimbabwe. This is a significant shortcoming in a setting with a high prevalence of CP. ${ }^{11}$ Further, with the advent of the client-centred approach, caregiver education has evolved as a prerequisite for optimal rehabilitation outcomes. ${ }^{18}$ Therefore, this study was carried out to evaluate the impact of an educational intervention on caregivers' levels of CP knowledge.

\section{Methods \\ Study design}

A comparative, descriptive cross-sectional study was conducted between July 2014 and June 2015. In terms of knowledge about $\mathrm{CP}$, caregivers who had undergone $\mathrm{CP}$ workshops were compared with caregivers who did not receive any formal CP-related guidance.

\section{Setting}

The study was carried out at the Parirenyatwa Group of Hospitals and Harare Central Hospital, which are the two largest referral, tertiary healthcare institutions in Harare, Zimbabwe.

\section{Interventions}

The Children's Rehabilitation Unit (CRU) at Harare Central Hospital is the largest paediatric rehabilitation referral centre in Zimbabwe. ${ }^{11}$ The CRU holds workshops for caregivers of children with $\mathrm{CP}$ on a monthly basis under ideal circumstances. During these workshops, caregivers are taught on the presentation, aetiology, and management of CP. These workshops are facilitated by physiotherapists, occupational therapists, counsellors, and rehabilitation technicians at the CRU. Further, other healthcare professionals, such as nurses and doctors, may be called in to give specific health education talks. For instance, a nurse can be called in to provide a health talk on prenatal, perinatal, and postnatal care. Unfortunately, at present there is no standardised curriculum to guide the facilitation of these workshops. Additionally, as part of the educational workshop, caregivers are given the chance to share their experiences in taking care of a child with CP. Further, the caregivers also receive psychosocial support in the form of individual counselling sessions. At the end of the three-day workshop, the children receive individual assessments and treatment from rehabilitation personnel. As for the Parirenyatwa Group of Hospitals, the children with $\mathrm{CP}$ receive rehabilitation services on an outpatient basis, and at present, the hospital does not run support groups for caregivers of children with CP.

\section{Participants}

Participants in this study were caregivers of children with CP who had either attended CP workshops or had not attended such workshops. Primary and informal caregivers of children diagnosed of $\mathrm{CP}$ were recruited.

\section{Sampling and sample size calculation}

Convenience sampling was used. In a similar study carried out in Nigeria, $70 \%$ of the caregivers were knowledgeable about CP. ${ }^{19}$ Assuming 50\% of respondents in the present study to be knowledgeable, the expected minimum number of cases was 46, at a $95 \%$ confidence level and $80 \%$ power. The sample size was calculated using Statistica (version 12) statistical software.

\section{Instrument}

In our literature review, we did not come across a standardised and psychometrically sound tool for measuring caregiver knowledge levels about CP. Accordingly, we developed the Knowledge of Cerebral Palsy Questionnaire (KCPQ) through a five-stage process. We initially performed a review of the relevant literature to identify related tools, after which we extracted an initial list of candidate items. We then interviewed five healthcare professionals to elicit some of the context-specific questions for inclusion. We also interviewed 10 caregivers of children with $\mathrm{CP}$ to gain insight into what they would expect to learn and what they want to know about CP. Thereafter, we drafted the initial versioin, which was evaluated for face validity by a panel of five experts. Thereafter, the preliminary version was then administered to a group of 10 caregivers for cognitive debriefing. The second draft was then administered to a larger sample of caregivers $(\mathrm{N}=49)$ for further psychometric evaluation. Preliminary psychometric evaluation has demonstrated the KCPQ to be internally consistent, with a Cronbach's alpha $(\alpha)$ value of 0.891 , and to be stable, with a reliability coefficient ( $r$ ) of 0.80 . The panel of experts endorsed the face validity of the tool. Further, the tool yielded a content validity index (CVI) of 0.850 and displayed a four-factor structure, thus demonstrating its validity. Therefore, the KCPQ has been demonstrated to be a reliable and valid tool in measuring the level of knowledge of CP amongst Zimbabwean caregivers.

\section{Ethical considerations}

Ethical approval was granted by the Medical Research Council of Zimbabwe (MRCZ/B/760). Institutional approvals were granted by Harare Central Hospital and the Parirenyatwa Group of Hospitals. Informed written consent was obtained from the caregivers. Caregivers were assigned identity numbers to preserve confidentiality, and only the principal researcher had access to the collected raw data, which was kept in a safe locker.

\section{Data analysis}

Descriptive statistics were used to present the sociodemographics. The Mann-Whitney $U$ test, the independent t-test, and Fisher's exact test were used to compare the two groups. The analysis of data was done using Statistica (version 12) statistical software. P-values $\leq$ 0.05 were considered statistically significant.

\section{Results}

\section{Sociodemographic characteristics}

As shown in Table 1 , most of the caregivers were mothers ( $\mathrm{n}$ $=24 ; 80 \%)$, married $(\mathrm{n}=28 ; 96.7 \%)$, unemployed $(\mathrm{n}=18$; $60 \%$ ), and all caregivers were literate.

\section{Knowledge about cerebral palsy}

Outlined in Table 2 are frequencies of the study sample's responses to the KCPQ.

Caregivers responded correctly to most of the KCPQ questions, as the percentage of correct responses were in the 
Table 1: Sociodemographic characteristics of caregivers and children

Attended CP

Variable

workshop before

Never attended CP

workshop

Total

Statistic

P-value

$\mathrm{N}=\mathbf{2 5} \mathrm{N}=\mathbf{2 4}$

Age of children with CP (months)

Median (range)

$36(12-144)$

$20(3-132)$

$30(3-144)$

$\mathrm{U}=141.5$

$Z=3.16$

0.001

Caregiver's age (years)

Mean \pm standard

deviation

$31 \pm 5.8$

$30 \pm 7.9$

$30 \pm 6.8$

$\mathrm{t}=5.41$

$\mathrm{df}=47$

Caregiver's marital status - n (\%)

Married $24(96.0)$

$20(83.3)$

$44(89.8)$

Fisher's

Single

$1(4.0)$

4 (16.7)

$5(10.2)$

exact

Caregiver's highest educational level — n (\%)

$\begin{array}{lcc}\text { Primary } & 3(12.0) & 4(16.7) \\ \text { Secondary } & 19(76.0) & 16(66.7) \\ \text { Tertiary } & 3(12.0) & 4(16.7)\end{array}$

Fisher's

exact

Caregiver's relationship to child - n (\%)
Mother
$1(4)$
Caregiver's employment status — n (\%)

$\begin{array}{lc}\text { Unemployed } & 14(56.0) \\ \text { Informally employed } & 9(36.0) \\ \text { Formally employed } & 2(8.0)\end{array}$
$18(75.0)$
$4(16.7)$

$32(65.3)$

$11(22.4)$

$6(12.2)$

exact

$\begin{array}{ll}\text { Fisher's } & \\ \text { exact } & 0.064\end{array}$

$\mathrm{CP}=$ cerebral palsy

range of $80 \%$ to $100 \%$. Question 15 ("Cerebral palsy can be cured: yes/no") was the most incorrectly answered question, with $70 \%(\mathrm{n}=21)$ of the caregivers giving incorrect answers.

\section{Subanalysis of the subscores}

The maximum possible subscores on the KCPQ were as follows: 3 for definition, 6 for aetiology, 5 for presentation, 6 for management, making the maximum possible total score 20 .

As can be seen in Table 3, caregivers who attended workshops had significantly higher KCPQ scores (both in terms of total scores and subscores) than caregivers who had not attended CP workshops before.

\section{Discussion}

The two groups of caregivers were comparable in terms of sociodemographics, except for the age of the children, and therefore the differences in knowledge may largely be attributable to exposure to educational workshops. However, it should be noted that the median age of children whose caregivers attended a CP workshop was significantly (by 16 months) greater than the median age of children whose caregivers did not attend a workshop. This extra experience in taking care of children with $\mathrm{CP}$ may have contributed to the higher scores among workshop attendees. The age differences can partly be explained by the way workshops are scheduled. When a child is diagnosed with CP, his or her

name is booked for participation in a future CP workshop. In some instances, the workshop can happen several weeks to months later, owing to financial constraints, as the CRU provides food, accommodation, and travel expenses for all workshop attendees. Additionally, convenience sampling was used to select participants, and the possibility of selection bias cannot be ruled out.

\section{Caregivers' knowledge about the definition of cerebral palsy}

Caregivers who attended a workshop were more knowledgeable about the definition of CP. Under normal circumstances, it is expected that caregivers should receive an explanation of the term cerebral palsy at the time of diagnosis. However, given the complexity of the definition, caregivers can take time to consolidate this information, ${ }^{4}$ thus the difference in knowledge can be attributed to other sources of information. Additionally, in low-resource settings, time constraints may lead overburdened healthcare personnel to provide parents and guardians with incomplete information about such a complex diagnosis. Cargivers' dissatisfaction with the extent of communication provided by rehabilitation professionals has been previously demonstrated in this setting. ${ }^{11}$ A study carried out Nigeria found that caregivers of children with cerebral palsy who received rehabilitation 
Table 2: Correct and incorrect responses on the Knowledge of Cerebral Palsy Questionnaire (KCPQ)

\begin{tabular}{|c|c|c|c|c|c|c|}
\hline \multirow[b]{2}{*}{ Knowledge statement } & \multicolumn{2}{|c|}{$\begin{array}{c}\text { Attended cerebral palsy } \\
\text { workshop } \\
\text { N }=25\end{array}$} & \multicolumn{2}{|c|}{$\begin{array}{l}\text { Never attended cerebral } \\
\text { palsy workshop } \\
\mathrm{N}=24\end{array}$} & \multicolumn{2}{|c|}{$\begin{array}{l}\text { All participants } \\
\qquad \mathrm{N}=49\end{array}$} \\
\hline & $\begin{array}{c}\text { Correct } \\
\text { response } \\
\text { n }(\%)\end{array}$ & $\begin{array}{c}\text { Incorrect } \\
\text { response } \\
\text { n }(\%)\end{array}$ & $\begin{array}{c}\text { Correct } \\
\text { response } \\
\text { n (\%) }\end{array}$ & $\begin{array}{l}\text { Incorrect } \\
\text { response } \\
\text { n }(\%)\end{array}$ & $\begin{array}{l}\text { Correct } \\
\text { response } \\
\text { n (\%) }\end{array}$ & $\begin{array}{c}\text { Incorrect } \\
\text { response } \\
\text { n (\%) }\end{array}$ \\
\hline $\begin{array}{l}\text { 1. Cerebral palsy is caused by injury to the developing } \\
\text { brain. }\end{array}$ & $24(96.0)$ & $1(4.0)$ & $19(79.2)$ & $5(20.8)$ & $43(87.8)$ & $6(12.2)$ \\
\hline $\begin{array}{l}\text { 2. Children with cerebral palsy are at a high risk of } \\
\text { suffering from seizures/epilepsy. }\end{array}$ & $21(84.0)$ & $4(16.0)$ & $16(66.7)$ & $8(33.3)$ & $37(75.5)$ & $12(24.5)$ \\
\hline $\begin{array}{l}\text { 3. Children with cerebral palsy may attain developmental } \\
\text { milestones, such as rolling, sitting, at a late stage when } \\
\text { compared to children of similar age. }\end{array}$ & $25(100.0)$ & 0 & $22(91.7)$ & $2(8.3)$ & $47(95.9)$ & $2(4.1)$ \\
\hline $\begin{array}{l}\text { 4. Difficulties during child birth process, such as } \\
\text { prolonged labour, may predispose the child to acquiring } \\
\text { cerebral palsy. }\end{array}$ & $24(96.0)$ & $1(4.0)$ & $19(79.2)$ & $5(20.8)$ & $43(87.8)$ & $6(12.2)$ \\
\hline $\begin{array}{l}\text { 5. A child may develop cerebral palsy if they do not cry } \\
\text { soon after birth. }\end{array}$ & $22(88.0)$ & $3(12.0)$ & $15(62.5)$ & $9(37.5)$ & $37(75.5)$ & $12(24.5)$ \\
\hline 6. Cerebral palsy may be as a result of witchcraft. & $22(88.0)$ & $3(12.0)$ & $12(50.0)$ & $12(50.0)$ & $34(69.4)$ & $15(30.6)$ \\
\hline $\begin{array}{l}\text { 7. If a pregnant woman is promiscuous during pregnancy, } \\
\text { it may lead in the child acquiring cerebral palsy. }\end{array}$ & $17(68.0)$ & $8(32.0)$ & $8(33.3)$ & $16(66.7)$ & $25(51.0)$ & $24(49.0)$ \\
\hline $\begin{array}{l}\text { 8. Cerebral palsy may be as a result of punishment by } \\
\text { ancestral spirits. }\end{array}$ & $20(80.0)$ & $5(20.0)$ & $18(75.0)$ & $6(25.0)$ & $38(77.6)$ & $11(22.4)$ \\
\hline $\begin{array}{l}\text { 9. If a child suffers from jaundice after birth, they may } \\
\text { have high chances of acquiring cerebral palsy. }\end{array}$ & $20(80.0)$ & $5(20.0)$ & $11(45.8)$ & $13(54.2)$ & $31(63.3)$ & $18(36.7)$ \\
\hline $\begin{array}{l}\text { 10. Most children with cerebral palsy present with stiff } \\
\text { limbs or muscles. }\end{array}$ & $21(84.0)$ & $4(16.0)$ & $11(45.8)$ & $13(54.2)$ & $32(65.3)$ & $17(34.7)$ \\
\hline 11. Children with cerebral palsy may have floppy limbs. & $24(96.0)$ & $1(4.0)$ & $17(70.8)$ & $7(29.2)$ & $41(83.7)$ & $8(16.3)$ \\
\hline $\begin{array}{l}\text { 12. Children with cerebral palsy may have difficulties in } \\
\text { learning. }\end{array}$ & $17(68.0)$ & $8(32.0)$ & $14(58.3)$ & $10(41.7)$ & $31(63.3)$ & $18(36.7)$ \\
\hline $\begin{array}{l}\text { 13. Some children with severe cerebral palsy may have } \\
\text { difficulties with chewing and feeding. }\end{array}$ & $25(100.0)$ & 0 & $18(75.0)$ & $6(25.0)$ & $43(87.8)$ & $6(12.2)$ \\
\hline $\begin{array}{l}\text { 14. Saliva drooling can persist in children with cerebral } \\
\text { palsy. }\end{array}$ & $21(84.0)$ & $4(16.0)$ & $20(83.3)$ & $4(16.7)$ & $41(83.7)$ & $8(16.3)$ \\
\hline 15. Cerebral palsy can be cured. & $12(48.0)$ & $13(52.0)$ & $2(8.3)$ & $22(91.7)$ & $14(28.6)$ & $35(71.4)$ \\
\hline $\begin{array}{l}\text { 16. Exercises are important in the management of a child } \\
\text { with cerebral palsy. }\end{array}$ & $23(92.0)$ & $2(8.0)$ & $22(91.7)$ & $2(8.3)$ & $45(91.8)$ & $4(8.2)$ \\
\hline $\begin{array}{l}\text { 17. Assistive devices such as corner sit may be } \\
\text { recommended in the management of a child with cerebral } \\
\text { palsy. }\end{array}$ & $24(96.0)$ & $1(4.0)$ & $21(87.5)$ & $3(12.5)$ & $45(91.8)$ & $4(8.2)$ \\
\hline $\begin{array}{l}\text { 18. Rehabilitation professionals may assist in training } \\
\text { children with cerebral palsy in daily activities, such as } \\
\text { feeding, grooming among others. }\end{array}$ & $25(100.0)$ & 0 & $24(100.0)$ & 0 & $49(100.0)$ & 0 \\
\hline $\begin{array}{l}\text { 19. Participation in self-help groups to share ideas and } \\
\text { experiences with caregivers of children with cerebral palsy } \\
\text { is essential. }\end{array}$ & $24(96.0)$ & $1(4.0)$ & $22(91.7)$ & $2(8.3)$ & $46(93.9)$ & $3(6.1)$ \\
\hline $\begin{array}{l}\text { 20. If a child with cerebral palsy gets early treatment, they } \\
\text { are likely to improve more. }\end{array}$ & $24(96.0)$ & $1(4.0)$ & $21(87.5)$ & $3(12.5)$ & $45(91.8)$ & $4(8.2)$ \\
\hline
\end{tabular}


Table 3: Knowledge of Cerebral Palsy Questionnaire (KCPQ) scores

\begin{tabular}{|c|c|c|c|c|}
\hline \multirow[b]{2}{*}{ CP knowledge domain } & \multicolumn{2}{|c|}{ KCPQ subscore } & \multirow[b]{2}{*}{ Statistic } & \multirow[b]{2}{*}{ P-value } \\
\hline & $\begin{array}{c}\text { Attended } \\
\text { CP workshop } \\
(\mathrm{N}=25)\end{array}$ & $\begin{array}{l}\text { Never attended } \\
\text { CP workshop } \\
(\mathrm{N}=24)\end{array}$ & & \\
\hline \multicolumn{5}{|l|}{ CP definition } \\
\hline Mean \pm standard deviation & $2.80 \pm 0.50$ & $2.38 \pm 0.77$ & $\mathrm{U}=208.0$ & 0.024 \\
\hline Median (range) & $3.0(1-3)$ & $3.0(1-3)$ & $Z=-1.83$ & \\
\hline \multicolumn{5}{|l|}{ Aetiology } \\
\hline Mean \pm standard deviation & $5.00 \pm 1.00$ & $3.46 \pm 1.19$ & $\mathrm{U}=102.0$ & $<0.001$ \\
\hline Median (range) & $5.0(3-6)$ & $3.5(2-6)$ & $Z=-3.95$ & \\
\hline \multicolumn{5}{|l|}{ Clinical presentation } \\
\hline Mean \pm standard deviation & $4.32 \pm 0.75)$ & $3.33 \pm 1.34$ & $\mathrm{U}=168.5$ & 0.006 \\
\hline Median (range) & $4.0(3-5)$ & $3.5(1-5)$ & $Z=-2.62$ & \\
\hline \multicolumn{5}{|l|}{ Management } \\
\hline Mean \pm standard deviation & $5.28 \pm 0.68$ & $4.67 \pm 0.64$ & $\mathrm{U}=165.5$ & 0.003 \\
\hline Median (range) & $5.0(4-6)$ & $5.0(3-6)$ & $Z=-2.68$ & \\
\hline \multicolumn{5}{|l|}{ Total KCPQ score } \\
\hline Mean \pm standard deviation & $17.40 \pm 1.53$ & $13.83 \pm 2.51$ & $\mathrm{U}=77.0$ & $<0.001$ \\
\hline Median (range) & $17.0(15-20)$ & $13.0(9-18)$ & $Z=-4.45$ & \\
\hline
\end{tabular}

$\mathrm{CP}=$ cerebral palsy

services could only refer to their children's condition using the abbreviation "CP"; they did not know what the acronym stands for and were unable to define it. ${ }^{25}$ Shame, ignorance, and fear of being scolded were cited as reasons why caregivers did not ask healtcare professionals for clarification. ${ }^{25}$ However, respondents in the Nigerian study were able to give correct responses after an educational intervention, and this could be the same for caregivers who attended workshops in the present study. In a workshop setting, caregivers are provided an open and conducive enivronment, where they have ample time to ask any pertinent questions.

\section{Caregivers' knowledge about the aetiology of cerebral palsy}

As expected, caregivers who had undergone an educational workshop were more knowledgeable with regards to the aetiology of CP. During the workshop, caregivers are given lectures on the aetiology of the condition. Caregivers are also given the chance to discuss the possible aetiology of their child's condition. This is especially important in an environment where some myths about what causes $\mathrm{CP}$ are still prevalent. For instance, there are beliefs in some African societies that $\mathrm{CP}$ can result from witchcraft, maternal promiscuity, and bad omens, among others. ${ }^{13,26,27}$ In this regard, the positive impact of the workshops is evidenced by the proportion of attendees who were aware that witchcraft $(\mathrm{n}=22.0 ; 88.0 \%)$, promiscuity $(\mathrm{n}=17.0 ; 68.0 \%)$, and punishment by ancestral spirits $(\mathrm{n}=20.0 ; 80.0 \%)$ do not influence the development of CP. In a similar study, interviews were carried out before and after exposure to an educational film to determine its impact on knowledge http://dx.doi.org/10.4314/mmj.v28i4.4 among parents of children with CP ( $\mathrm{n}=53)$. The parents displayed a statistically significant increase $(\mathrm{P}<0.001)$ in their knowledge about the causes of $\mathrm{CP}$ after watching the film, with $90.6 \%$ recording correct responses, versus an initial correct response proportion of $26.4 \% .{ }^{25}$

\section{Caregivers' knowledge about the clinical presentation of cerebral palsy}

Given the multiple teaching strategies and methods applied during the workshops, it was unsurprising that caregivers who had attended at least one workshop had more knowledge about the clinical presentation of CP. The utilisation of practical demonstrations, pictures, and short video clips could have reinforced the caregivers' understanding of the presentation of CP. Further, at the end of each workshop, therapists perform individual assessments and treatments, and give feedback to caregivers. This further reinforces caregivers' understanding of the presentation of CP. It is known that children with $\mathrm{CP}$ present in different ways, depending on the area of the brain that is affected. ${ }^{22,28}$ During the workshops caregivers are given the opportunity to learn about other subtypes of $\mathrm{CP}$ by observing other children attending the workshop.

\section{Caregivers' knowledge about the management of cerebral palsy}

Although CP has no cure, rehabilitation provision has been demonstrated to be of tremendous benefit. ${ }^{10,31}$ As part of the CP workshop programme, children receive one-on-one treatment, as well as group therapy sessions. Caregivers are required to demonstrate to other caregivers the prescribed 
home exercise programmes to reinforce their learning, so as to improve the efficacy of the execution of the exercises. It is against this background that differences in knowledge could be attributed to workshop attendance. Further, caregivers are also educated on the benefits of rehabilitation techniques, such as therapeutic exercises, by the health professionals during the workshops.

Caregivers who attended workshops agreed that participation in self-help groups helped reduce caregiver burden. During the workshops, caregivers are given a chance to share experiences and coping mechanisms. There is empirical evidence that social support is essential in mitigating caregiver burden. ${ }^{20,32}$ Further, workshops are an excellent platform for networking, and caregivers are also encouraged to form self-help groups. Elsewhere, some caregivers have reported that they find it challenging to discuss the management of $\mathrm{CP}$ with health professionals, out of fear of being labelled ignorant about topics that a caregiver of a child with $\mathrm{CP}$ should know well already. ${ }^{33}$

\section{Conclusions}

The findings of this cross-sectional study should be interpreted with caution, as confounding variables were not adjusted for. For instance, the potential effect of the Internet as an information source ${ }^{34}$ was not accounted for. Moreover, given the high literacy rate of the caregivers, differences in knowledge about CP may not be entirely attributable to exposure to workshops. Further, there is a lack of a standardised curriculum to guide the facilitation of the educational workshops, which makes it difficult to attribute the changes of knowledge to specific aspects of workshop attendance. However, evidence from the current study still suggests the efficacy of workshops in increasing caregivers' knowledge levels about CP. Therefore, we recommend that healthcare professionals make deliberate efforts, using structured interventions (formal workshop curricula, for example), to educate caregivers about CP. There is also need to carry out further studies to evaluate the impact of these workshops over a long period, through use of longitudinal designs.

\section{Competing interests}

The authors declare that they have no competing interests.

\section{Acknowledgements}

We would like to acknowledge the invaluable participation of the caregivers of children with cerebral palsy at the study sites.

\section{References}

1. Schuengel C, Rentinck ICM, Stolk J, et al. Parents' reactions to the diagnosis of cerebral palsy: associations between resolution, age and severity of disability. Child Care Health Dev. 2009;35(5):673-681. doi:10.1111/j.1365-2214.2009.00951.x.

2. Graungaard AH, Skov L. Why do we need a diagnosis? A qualitative study of parents 'experiences, coping and needs, when the newborn child is severely disabled. Child care, Heal Dev. 2006;33(3):296-307. doi:10.1111/j.1365-2214.2006.00666.x.

3. Rentinck ICM, Ketelaar M, Schuengel C, et al. Short-term changes in parents' resolution regarding their young child's diagnosis of cerebral palsy. Child Care Health Dev. 2010;36(5):703-708. doi:10.1111/j.13652214.2010.01077.x.

4. Shevell AH, Shevell M. Doing the "talk": disclosure of a diagnosis of cerebral palsy. J Child Neurol. 2013;28(2):230-235. doi:10.1177/0883073812471430.
5. Baird G, McConachie H, Scrutton D. Parents' perceptions of disclosure of the diagnosis of cerebral palsy. Arch Dis Child. 2000;83(6):475-480. doi:10.1136/adc.83.6.475.

6. Martin B, Murray G, Peter R, Alan L, Nigel P. Proposed definition and classification of cerebral palsy, April 2005.pdf. Dev Med Child Neurol. 2005;47(571):571-576.

7. Blair E, Watson L. Epidemiology of cerebral palsy. Seminars in Fetal \& Neonatal Medicine. doi:10.1016/j.siny.2005.10.010.

8. Berker AN, Yalçin MS. Cerebral palsy: orthopedic aspects and rehabilitation. Pediatr Clin North Am. 2008;55(5):1209-1225, ix. doi:10.1016/j.pcl.2008.07.011.

9. O'Shea TM. Diagnosis, Treatment, and Prevention of Cerebral Palsy in Near- Term/Term Infants. Clin Obstet Gynecol J. 2008;51(4):816-828. doi:10.1097/GRF.0b013e3181870ba7.Diagnosis.

10. Jones MW, Morgan E, Shelton JE, Thorogood C. Cerebral palsy: introduction and diagnosis (part I). J Pediatr Health Care. 2007;21(3):146152. doi:10.1016/j.pedhc.2006.06.007.

11. Dambi JM, Jelsma J. The impact of hospital-based and community based models of cerebral palsy rehabilitation : a quasi-experimental study. BMC Pediatr. 2014;14(301):1-10. doi:10.1186/s12887-014-0301-8.

12. Pousada M, Guillamón N, Hernández-Encuentra E, et al. Impact of Caring for a Child with Cerebral Palsy on the Quality of Life of Parents: A Systematic Review of the Literature. J Dev Phys Disabil. 2013;25(5):545577. doi:10.1007/s10882-013-9332-6.

13. Dambi JM, Jelsma J, Mlambo T. Caring for a child with Cerebral Palsy: The experience of Zimbabwean mothers. African J Disabil. 2015;4(1):110. doi:10.4102/ajod.v4i1.168.

14. Dambi JM, Makotore FG. The Impact of Caregiving a Child with Cancer: A Cross Sectional Study of Experiences of Zimbabwean Caregivers. J Palliat Care Med. 2015;05(05). doi:10.4172/21657386.1000230 .

15. Reid CE, Moss S, Hyman G. Caregiver Reciprocity: The effect of reciprocity, carer self-esteem and motivation on the experience of caregiver burden. Aust J Psychol. 2005;57(3):186-196. doi:10.1080/00049530500141022.

16. Raina P, Donnell MO, Schwellnus H, et al. Caregiving process and caregiver burden: Conceptual models to guide research and practice. BMC Pediatr. 2004;4(1):1-13.

17. Cheshire A, Barlow JH, Powell LA. The psychosocial well-being of parents of children with cerebral palsy: a comparison study. Disabil Rehabil. 2010;32(20):1673-1677. doi:10.3109/09638281003649920.

18. Arora SK, Aggarwal A, Mittal H. Impact of an educational film on parental knowledge of children with cerebral palsy. Int J Pediatr. 2014;2014:573698. doi:10.1155/2014/573698.

19. Olawale OA, Deih AN, Yaadar RKK. Psychological impact of cerebral palsy on families: The African perspective. J Neurosci Rural Pract. 2013;4(2):159-163. doi:10.4103/0976-3147.112752.

20. Oh H, Lee EO. Caregiver Burden and Social Support among Mothers Raising Children with Developmental Disabilities in South Korea. Int J Disabil , Dev Educ. 2009;56(2):149-167. doi:10.1080/10349120902868624.

21. Boström PK, Broberg M, Hwang P. Parents' descriptions and experiences of young children recently diagnosed with intellectual disability. Child Care Health Dev. 2010;36(1):93-100. doi:10.1111/j.13652214.2009.01036.x.

22. Jahagirdar S. Occupational therapy psycho-educational group: empowering cagivers of children with cerebral palsy. Indian J Occup Ther. 2012;44(2):14-23.

23. Benzies KM, Magill-evans J., Hayden K., Ballantyne M. Key components of early intervention programs for preterm infants and their parents : a systematic review and meta-analysis. BMC Pregnancy Childbirth. 2013;13(1):1-15. doi:10.1186/1471-2393-13-S1-S10.

24. Kynø N., Ravn I., Lindemann R, Smeby N., Torgersen A. Parents of preterm-born children; sources of stress and worry and experiences with an early intervention programme - a qualitative study. BMC Nurs. 2013;12(28):1-11. 
25. Arora SK, Aggarwal A, Mittal H. Impact of an Educational Film on Parental Knowledge of Children with Cerebral Palsy. Int J Pediatr. 2014;1(1):1-4. doi:10.1155/2014/573698.

26. Hamzat TK, Mordi EL. Impact of Caring for Children with Cerebral Palsy on the General Health of Their Caregivers in an African Community - International journal of rehabilitation research .2007;30(3):191-4. doi:10.1097/MRR.0b013e3281e5af46.

27. Myezwa H, M'kumbuzi V. Participation in community based rehabilitation programmes in Zimbabwe: where are we? Asia Pacific Disabil Rehabil J. 2003;14(1):18-29.

28. Rethlefsen S a, Ryan DD, Kay RM. Classification systems in cerebral palsy. Orthop Clin North Am. 2010;41(4):457-467. doi:10.1016/j. ocl.2010.06.005.

29. Sellers D, Pennington L, Mandy A, Morris C. A systematic review of ordinal scales used to classify the eating and drinking abilities of individuals with cerebral palsy. Dev Med Child Neurol. 2014;56:313-322. doi:10.1111/dmen.12313.
30. Gautam NS, Dola S., Gautam N., Koganti R, Thota H., Goud A. Lip Position and Drooling of Saliva in Children With Cerebral Palsy. J Res Adv Dent. 2014;3(1):212-215.

31. Jones MW, Morgan E, Shelton J., Thorogood C. Cerebral Palsy: Introduction and Diagnosis ( Part I ) PALSY. J Pediatr Heal Care. 2007;21(3):146-152. doi:10.1016/j.pedhc.2006.06.007.

32. Skok A, Harvey D, Reddihough D. Perceived stress, perceived social support, and wellbeing among mothers of school-aged children with cerebral palsy. J Intellect Dev Disabil. 2006;31(1):53-57. doi:10.1080/13668250600561929.

33. Ablewhite J, Kendrick D, Watson M, Shaw I. The other side of the story - maternal perceptions of safety advice and information: a qualitative approach. Child Care Health Dev. 2015. doi:10.1111/cch.12224.

34. Adler K, Salanter S, Leino-kilpi H, Gradel B. An Integrated Literature Review of the Knowledge Needs of Parents With Children With Special Health Care Needs and of Instruments to Assess These Needs. Infants \&Young Child. 2015;28(1):46-71. doi:10.1097/IYC.0000000000000028. 